\title{
Esquerdo sobre direito: uma investigação sobre a semiótica do abotoamento de paletós masculinos
}

Left over right: an investigation into semiotic of male buttoning

[resumo] A despeito de todas as oscilações da moda, o padrão de abotoamento das roupas tem permanecido basicamente o mesmo há já, pelo menos, dois séculos: lado esquerdo sobre o lado direito para as roupas masculinas, e lado direito sobre o lado esquerdo para as roupas femininas. Isso vale igualmente para paletós, sobretudos, casacas, coletes etc. 0 objetivo deste artigo é, por um lado, compreender como se deu o surgimento dessa regra no caso das roupas masculinas e, por outro, analisar o simbolismo que deve ter contribuído para que essa regra não tenha se alterado com o passar do tempo.

\section{palavras-chave}

\section{abotoamento; botão; paletó; indumentária} masculina.

[abstract] The vagaries of fashion notwithstanding, the pattern of clothes buttoning has been basically the same for over two centuries by now: left over right for male garments, and right over left for female garments. This rule holds equally for coats, overcoats, frock coats, vests etc. The present article seeks to understand, on the one hand, how this rule came into being, and on the other hand, to analyze how the symbolism behind this rule may have contributed for the endurance of the left over right way of buttoning.

[key words] fashion; buttoning; button; coat; male attire. 
A expressão: "Conversar com os seus botões", parecendo simples metáfora, é frase de sentido real e direto. Os botões operam sincronicamente conosco; formam uma espécie de senado, cômodo e barato, que vota sempre as nossas moções.

(Machado de Assis, Quincas Borba)

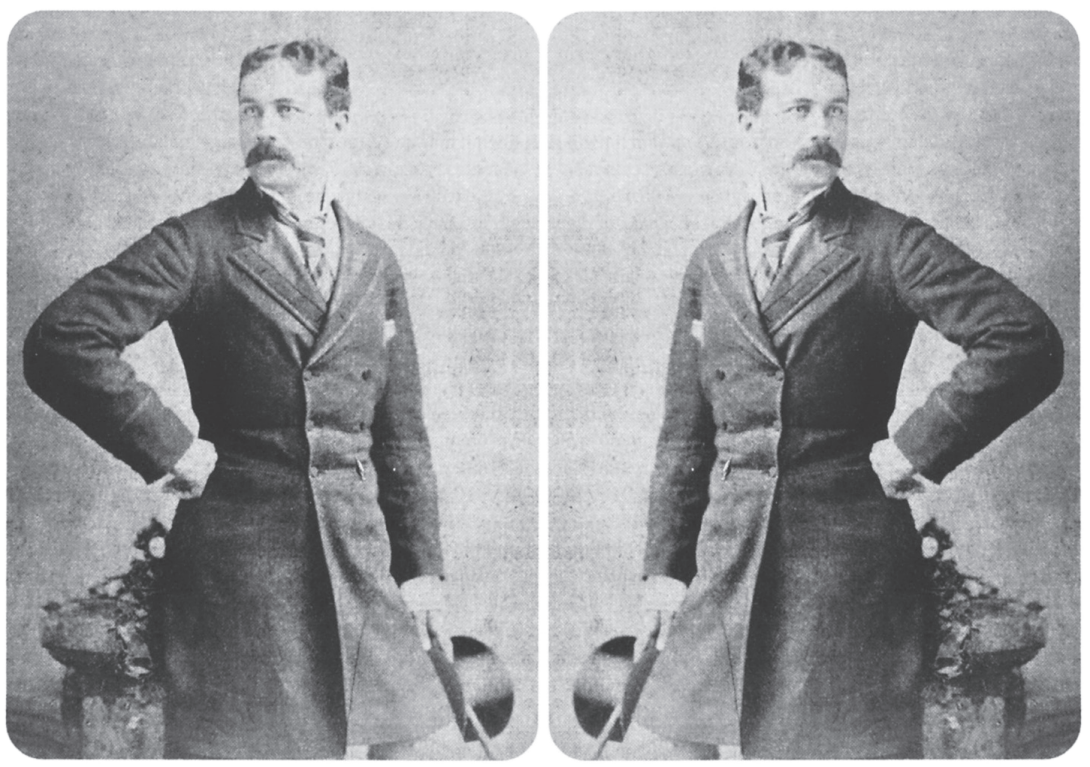

Joaquim Nabuco, 1878

Observe as duas imagens acima de Joaquim Nabuco, elegantemente posando de sobrecasaca e cartola na segunda metade do século dezenove: qual das duas fotos está invertida, e qual retrata corretamente a cena original? Muitas fotos antigas foram publicadas de modo inverso por engano, assemelhando-se a uma imagem vista no espelho. E ainda hoje não é raro observarmos fotos invertidas em propagandas de revistas e até mesmo em capas de livros, talvez menos por descuido de editores do que pelas exigências por vezes pouco razoáveis de programadores visuais. Quando encontramos em uma foto detalhes como, por exemplo, o letreiro de uma loja, ou um relógio pendurado na parede, é fácil sabermos se ela está ou não invertida. Outra forma de reconhecermos se uma foto está "espelhada" consiste em observar a posição do abotoamento dos paletós masculinos. A parte frontal esquerda de um paletó masculino se abotoa quase que invariavelmente sobre a parte frontal direita. $E$ isso vale também para sobretudos, coletes, casacas, sobrecasacas e camisas sociais. Com as roupas femininas se dá justamente o inverso. 0 Joaquim Nabuco da primeira foto, do lado esquerdo, corresponde, portanto, à imagem original.

Há, no entanto, algumas situações em que uma dada imagem pode dar a impressão de estar invertida, sem que isso resulte de um erro de publicação ou da reprodução inadequada dos negativos. A primeira exceção diz respeito a autorretratos. Em alguns quadros de Vincent van Gogh, por exemplo, tem-se, à primeira vista, a impressão de que as imagens foram invertidas por engano, ou que o famoso pintor, na pobreza, tinha de recorrer a roupas femininas por falta de opção, pois os botões aparecem do lado esquerdo, com a parte direita da roupa se sobrepondo à parte esquerda. Mas a impressão de que a imagem desses quadros de van Gogh foi erroneamente publicada de modo invertido é apenas ilusória. Um autorretrato é geralmente feito diante de um espelho, de modo que a imagem retratada sobre a tela aparece literalmente "espelhada". As 
roupas de van Gogh, apesar de rotas, seguiam o padrão tradicional para abotoamento de paletós masculinos. Há, porém, algumas exceções a essa característica distintiva de autorretratos, pois às vezes 0 artista faz alguns ajustes na pintura de modo a eliminar quaisquer vestígios da inversão causada pelo espelho utilizado para a realização do trabalho. Existem, por exemplo, alguns autorretratos de Rembrandt em que o famoso pintor neerlandês se retrata pintando em seu estúdio. Como o pintor era destro, ele se retratou na tela como se estivesse, de fato, empunhando pincel e paleta com a mão direita. No entanto, imagens de raio-x de algumas telas mostram que Rembrandt teria inicialmente se retratado nessas obras exatamente como ele se via no espelho, isto é, como se estivesse segurando o pincel e a paleta com a mão esquerda. Em seguida, para evitar aparecer na tela como canhoto, ele teria feito drásticas modificações na pintura de modo a eliminar quaisquer indícios de que seu retrato pudesse parecer uma imagem espelhada (WHITE e BUVELOT, 1999). Não é possivel ver detalhes como botões ou caseados nessas telas, mas é razoável supor que Rembrandt teria optado pela inversão do modo de abotoamento se os botões ou caseados estivessem visiveis.
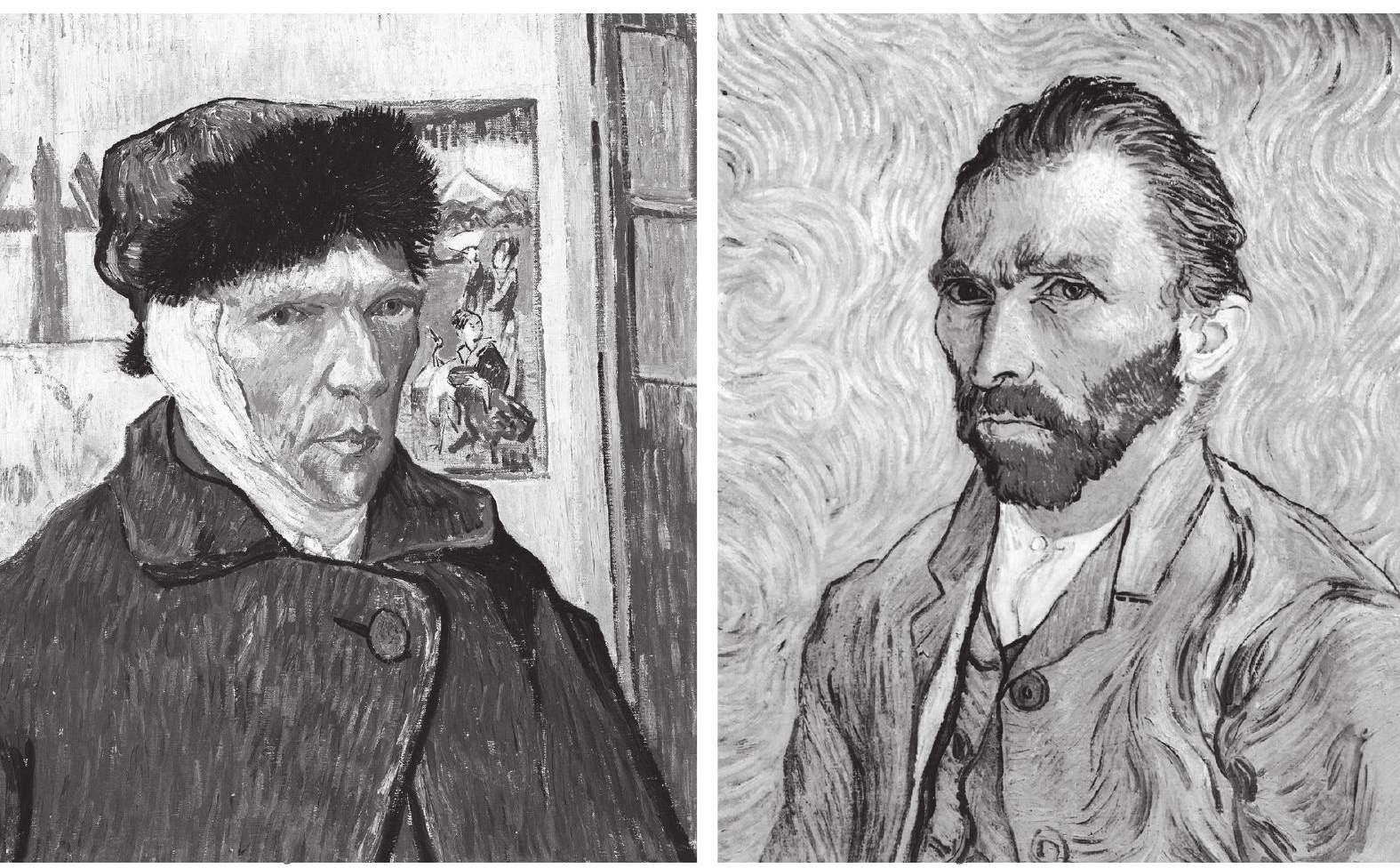

Outro tipo de situação em que uma foto pode dar erroneamente a impressão de estar invertida ocorre quando ela retrata um rekel ou kapote, ou seja, uma espécie de sobrecasaca com duas carreiras verticais de botões usada por alguns judeus da tradição chassídica. 0 reke/constitui uma exceção à regra de abotoamento de paletós masculinos porque ele segue um padrão de abotoamento tradicionalmente considerado próprio para roupas femininas, ou seja: direito-sobre-esquerdo. Embora explicações místicas tenham sido por vezes sugeridas para dar conta dessa particularidade do vestuário masculino chassídico, o mais provável é que o padrão de abotoamento do rekel tenha surgido como uma expressão da identidade cultural desse grupo religioso (JACOBS, 2008).

Originalmente, o rekel era utilizado na Europa tanto por judeus quanto por não judeus, sobretudo pelos membros da aristocracia polonesa. No entanto, com o passar do tempo, o rekel foi gradualmente caindo em desuso entre não judeus e, a partir de determinado momento, continuou sendo usado praticamente apenas entre os judeus chassídicos. No início do século XIX, uma questão que eles se colocaram, então, foi que tipo de alterações seriam aceitáveis em suas roupas, pois pretendiam garantir que fossem preservadas certas características distintivas do grupo religioso ao qual pertenciam. Aaron Wertheim (1992, p. 297) descreve esse debate nos seguintes termos: 
sendo o caseado para o botão confeccionado do lado esquerdo. ${ }^{2}$

Em outro verbete, acompanhado de algumas ilustrações, a famosa Enciclopédia descreve também as diversas técnicas e ferramentas usadas no ofício de boutonnier, 0 fabricante de botões. Uma das razões para que os autores da Enciclopédia dedicassem tanta atenção a algo aparentemente tão insignificante quanto um botão se explica pela existência de certas distinções sociais que os botões, naquela época, tinham o poder de operar. Nos séculos XVIII e XIX, de modo consciente ou não, era para os botões das roupas que se dirigia inicialmente o olhar das pessoas, mais ou menos da mesma forma como um vistoso candelabro tem a capacidade de capturar nosso olhar assim que adentramos no salão de um palácio. Dessa forma, os botões funcionavam como um importante indicativo da classe social a que pertenciam as pessoas. Quanto mais vistosos e elaborados fossem os botões e adornos das roupas, mais elevada era, pelo menos em princípio, a posição social da pessoa que as vestia. Segundo Melinda Watt $(2005$, p. 206209), as despesas com botões e bordados, dependendo do material que se empregava, poderia até mesmo ultrapassar mais da metade do valor total das roupas masculinas:

0 valor dos ornamentos no conjunto de roupas de um homem durante esse período, compostos de fios metálicos para bordados e botões de joalheiros, poderia representar até mesmo oitenta por cento do custo total das roupas. Assim, botões luxuosos se tornaram gradualmente uma parte essencial da expressão do status nas roupas dos homens da alta sociedade. (Tradução nossa)

Nos século XVIII e XIX, os botões se tornaram, frequentemente, verdadeiras obras de ourivesaria, e isso explica, inclusive, a razão pela qual colecionadores de botões têm uma predileção especial pelas peças dessa época. ${ }^{3}$ E justamente porque os botões estiveram por tanto tempo associados ao luxo e à ostentação, algumas comunidades religiosas Amish proíbem, ainda hoje, seus membros de usar botões em suas roupas, pois consideram os botões abomináveis sinais de luxúria e vaidade (HIBBERT e HIBBERT, 2005). Em instituições militares, os botões ainda são utilizados para demarcar patentes e regimentos. ${ }^{4}$ Dom Pedro II, por exemplo, tinha, nos botões de alguns de seus uniformes, a inscrição $P 2$. É talvez desnecessário mencionar que essa era uma prerrogativa do imperador. A diferença entre roupas civis e uniformes militares, em alguns tipos específicos de sobrecasaca, era marcada unicamente pelo tipo de botão utilizado (ARAUJO, 2012).

Aos poucos, com a disseminação dos ideais de "igualdade" e "fraternidade" propagados pela Revolução Francesa, os botões passaram a figurar tanto em roupas masculinas quanto em roupas femininas. Contudo, foi necessária outra revolução para que começassem a surgir de modo definitivo padrões de abotoamento diferentes para as roupas masculinas, de um lado, e para as roupas femininas, de outro. Com o advento da Revolução Industrial, as roupas começaram a ser produzidas em massa, e a adoção de certas convenções se tornou importante no processo de fabricação (MARLY, 1985).

No caso das roupas femininas, acredita-se que o padrão de abotoamento direito-sobre-esquerdo tenha sido estabelecido em função de um costume já vigente na época da Revolução Industrial. Como cabia às damas de companhia a tarefa de ajudar suas respectivas "damas" a trocar de roupa várias vezes durante o dia, e como, além disso, as damas de companhia eram geralmente destras, era mais simples e prático, para a empregada, abotoar e desabotoar as roupas de suas patroas se os botões fossem afixados do lado esquerdo da roupa. Dessa forma, eles seriam naturalmente manuseados com a mão direita da empregada. É desnecessário mencionar que a maior parte das mulheres não dispunha desse tipo de privilégio. Contudo, ao aderir ao padrão de abotoamento típico das roupas das mulheres da alta-sociedade, as mulheres mais pobres poderiam pelo menos aspirar a uma posição superior e mostrar publicamente que, pelo menos no que se referia ao abotoamento de suas roupas, elas desfrutavam de alguma respeitabilidade. ${ }^{5}$

No caso da indumentária masculina, acredita-se que o padrão de abotoamento tenha tido sua origem no antigo hábito de se carregar espadas do lado esquerdo da cintura. Como a maior parte dos homens é destra, a espada era carregada do lado esquerdo para que fosse possivel retirá-la rapidamente com a mão direita na iminên- 
cia de um confronto. Se a túnica de um incauto espadachim fosse abotoada como ainda hoje se abotoam roupas femininas, haveria então o risco de que o cabo de sua espada ficasse preso em sua roupa quando a lâmina fosse desembainhada às pressas. A falta de atenção para esse detalhe de sua roupa, como se pode imaginar, poderia muito bem lhe custar a vida. 0 abotoamento tradicional masculino - lado esquerdo sobre o direito - tinha, assim, uma função prática bastante relevante em duelos, disputas e combates. Mas alguns autores chegam mesmo a sugerir que o padrão de abotoamento masculino teria origens ainda mais antigas, se bem que não menos desvinculadas de situações de conflito armado. Graeme Donald (2009) sustenta que 0 padrão de abotoamento esquerdo-sobre-direito em roupas masculinas resulta de uma convenção que remonta à construção das primeiras armaduras medievais. As chapas de metal no torso da armadura eram dispostas segundo o esquema de esquerdo-sobre-direito porque - novamente -, como a maior parte dos homens era e continua sendo destra, os golpes desferidos para destruir a armadura viriam certamente do lado direito do oponente. A armadura se tornaria mais vulnerável aos golpes do inimigo se as chapas fossem dispostas de modo inverso. Como Donald (2009, p. 191) explica:

A tendência dominante, nas roupas masculinas de se abotoar esquerdo-sobre-direito é o resultado direito da estrutura e acabamento das primeiras armaduras. Todas as chapas e seções da armadura eram afixadas de modo esquerdo-sobre-direito como uma forma de defesa contra a maior parte dos golpes, que eram normalmente desferidos por um oponente destro, brandindo sua arma sobre o corpo do inimigo da esquerda para a direita. A configuração esquerdo-sobre-direito na armadura diminuía a possibilidade de os golpes do oponente penetrarem por sob uma das juntas. (Tradução nossa)

É bem verdade, porém, que já faz alguns séculos que os homens não andam mais por aí desfilando de armadura, ou carregando uma espada na cintura, a não ser como acessório de alguns uniformes militares, e mesmo assim apenas em algumas solenidades especiais. Por que então o modo de abotoamento dos paletós masculinos não oscilou com as vagarias da moda da mesma forma como, por exemplo, a altura da gola, o número de botões, ou o formato da lapela do paletó variaram com o tempo? A razão para a persistência do modo de abotoamento de roupas masculinas, a meu ver, é que os séculos passaram, mas a maior parte dos homens continua destra e precavida. Com o passar do tempo, os homens deixaram de carregar espadas porque passaram a portar outras armas - não menos letais. Se alguém tiver de esconder uma pistola ou revólver sob o paletó, será mais fácil sacá-lo rapidamente se a parte esquerda do paletó recobrir a parte direita - a não ser, é claro, que a pessoa em questão seja canhota. 0 coldre da pistola era geralmente escondido sob o lado esquerdo do paletó para que a arma pudesse ser alcançada com a mão direita. 0 abotoamento tradicional masculino permite que a mão direita deslize rapidamente para dentro do paletó sem que ela fique presa na roupa. Como se pode perceber, o modo tradicional de abotoamento de roupas masculinas deve ter sido preservado no século XX para atender à mesma função que ele já desempenhava na época dos espadachins.

Por outro lado, é preciso reconhecer que o número de homens circulando por aí com uma arma escondida sob o paletó deve ter gradualmente diminuído ao longo do século XX. Contudo, nem mesmo assim alfaiates ou designers ousaram mexer no tradicional modo de abotoamento de paletós masculinos. Durante um breve período na década de 1960 houve até mesmo uma onda de horrendos paletós sem gola ou lapela conhecidos como nehru e popularizados por Pierre Cardin e pelos Beatles (SCHOEFFLER e GALE, 1973). Em tudo se mexia no paletó, mas o padrão de abotoamento permaneceu o mesmo - lado esquerdo sobre o lado direito.

Talvez uma explicação para a permanência do padrão de abotoamento masculino possa ser buscada no cinema e em noticiários policiais. Ao longo do século XX, os ho- 
mens podem ter deixado suas armaduras e espadas em museus; revólveres e pistolas foram sendo gradualmente deixados em casa ou no porta-luvas do carro. Mas os homens continuaram indo ao cinema nas horas de lazer, e cenas como a de Humphrey Bogart, na foto de divulgação do filme Kid Galahad (1937), ou de personagens de filmes como Scarface (1983) e Pulp Fiction (1994), e até mesmo manchetes de jornais e noticiários policiais devem ter sido retidas inconscientemente na memória como uma indicação de que o abotoamento dos paletós masculinos não poderia ser de outro modo. 0 abotoamento tradicional, dessa forma, funcionaria como uma espécie de alusão inconsciente à ideia de poder e segurança que o porte de armas como pistolas e espadas parece ainda evocar. 0 paletó se transformou, ele próprio, numa espécie de armadura, num escudo de proteção para gangsters e acionistas da bolsa; ele se tornou o uniforme compulsório de legiões de juristas e políticos travando agora novas batalhas não menos decisivas em tribunais e parlamentos.

Essa não seria a primeira vez, aliás, que um item do guarda-roupa masculino assumiria esse tipo de função simbólica. Conta-se que, pouco antes de sua coroação como rei da França, em 1830, Louis Phillipe teria declarado preferir carregar um guarda-chuva a empunhar o cetro real:

A coroa da França é fria demais no inverno, quente demais no verão; 0 cetro é pouco afiado como arma de defesa ou ataque, ele é muito curto como uma bengala sobre a qual se possa apoiar: um bom chapéu de feltro e um guarda-chuva robusto são, a qualquer momento, muito mais úteis. (VANDAM, 2001, p. 276, tradução nossa)

A ideia de Louis Phillipe era ser visto por seus futuros súditos como uma pessoa comum. Os homens entenderam sua mensagem, e o resultado foi que o chapéu de feltro, que já coroava por toda parte a cabeça do cidadão comum, aliou-se ao guarda-chuva, que passou então a conferir a seus usuários um ar de austeridade e autoconfiança. A atitude de Louis Phillipe é relembrada em algumas passagens de $0 \mathrm{~s}$ Miseráveis, obra prima de Victor Hugo (1997, p. 570, tradução nossa):

Suas maneiras eram as do antigo regime, e seus hábitos, os do novo, uma mistura de nobre e burguês que convinha a 1830. Louis Philippe era uma transição reinante (...). Ele saía com seu guarda-chuva sob o braço, e esse guarda-chuva por um longo tempo foi uma porção de sua glória.

0 vínculo simbólico entre o uso de um singelo guarda-chuva e a segurança proporcionada por uma arma deve ter sido reforçado no imaginário masculino, mais de um século depois, quando a imprensa mundial cobriu o assassinato do escritor búlgaro Georgi Markov, morto em setembro de 1978, em Londres, por um agente do serviço secreto húngaro. A arma utilizada pelo assassino, como se descobriu mais tarde, era um prosaico guarda-chuva que disparava minúsculas cápsulas de um poderoso veneno. ${ }^{6}$

Se Louis Phillipe conferiu ao guarda-chuva o poder simbólico do cetro e da espada, coube a outro monarca francês imortalizar uma postura que, ainda hoje, é associada à ideia de masculinidade e aspiração ao poder. A postura em questão é a de Napoleão Bonaparte, retratado em uma infinidade de ocasiões com sua mão direita parcialmente oculta sob o colete. É importante enfatizar que Napoleão não criou essa pose, pois já bem antes dele outros homens haviam se deixado retratar da mesma forma (MEYER, 1995). Mas Napoleão certamente contribuiu para a perpetuação desse tipo de postura, levando muitos estadistas, generais, revolucionários e soberanos, incluindo-se aí Dom Pedro II e Karl Marx, a se deixar retratar da mesma forma em diversas pinturas e fotografias. Uma característica da pose napoleônica é que é a mão direita - raramente a mão esquerda - que se encontra parcialmente recoberta sob o paletó, sob a casaca ou sob o colete. Mas para que a mão direita possa ser elegantemente colocada nessa posição, é necessário que a casaca, paletó ou colete se feche com o lado esquerdo se sobrepondo ao lado direito. Do contrário, a fileira de botões da casaca, paletó, ou colete aparecerá desalinhada na altura da mão, perturbando, assim, a imagem de poder e masculinidade que a pose, sobretudo por influência de 


\section{Napoleão, passou a evocar.}

Um botão de roupa parece jamais ter tido uma posição de destaque nos corredores de algum museu. Na história da arte, sobre ele, praticamente nada se fala. A funcionalidade que exerce nas roupas que vestimos é simplória demais para servir de testemunho da inventividade humana. Bem mais engenhosos, com certeza, são, por exemplo, o zíper ou o velcro, devidamente patenteados por seus criadores. Apenas o poder simbólico que os botões adquiriram, e continuam a silenciosamente exercer, explica a persistência desses objetos em nosso cotidiano. Eles, como sugere Machado de Assis na epígrafe que antecede o presente artigo, "operam sincronicamente conosco", na mesma posição em que têm sido afixados desde sua introdução na cultura da indumentária masculina ocidental.

\section{NOTAS}

[1] Wertheim (1992, p. 298, tradução nossa) cita, por exemplo, a seguinte passagem de um dos líderes envolvidos nesse debate: Uma pessoa deve ser extremamente cuidadosa para não seguir o caminho dos não judeus, e deve estar separada deles em sua vestimenta e nos demais hábitos, de forma que não se misture com eles e não aprenda seus costumes". Veja também Rabinowicz (1989, p. 327, tradução nossa): "Abotoam seus paletós da direita para a esquerda. Qualquer inovação na vestimenta é considerada hukkat hagoy (imitação dos Gentios). Até mesmo usar colarinho e gravata é considerado, por alguns hassidim, como início de heresia. E ainda, Poll (2006, p. 66).

[2] Fonte: DIDEROT, D.; D'ALEMBERT, J. R. Encyclopédie ou dictionnaire raisonné des sciences, des arts et des métiers. V. 5. Paris: Briasson, 1781, p. 421.

${ }^{[3]}$ Segundo Watt (2005, p. 206, tradução nossa): "0 século XVIII é considerado a Era de Ouro dos botões por colecionadores, uma vez que tanto a variedade de estilos quanto o tamanho dos botões aumentam dramaticamente. Os paletós masculinos requeriam botões na abertura frontal, nas mangas, nos bolsos e nas aberturas de trás".

[4] De acordo com Watt (2005, p. 208, tradução nossa): "A padronização de uniformes militares na Europa do século XVIII levou à produção de botõ̃es especializados, que continua a ser a porção majoritária da indústria de botões atual. 0 número de botões necessários para o casaco de um soldado poderia variar de vinte a trinta. Cada país, região e especialização dentro das forças armadas demandava seus próprios designs individuais. Os botões dos uniformes transcenderam para a vida civil, visto que empresas modernas, como as linhas aéreas e algumas agências de polícia, requisitavam botões especiais para seus uniformes".

${ }^{[5]}$ Chrisp (2005, p. 44, tradução nossa) aponta: "Durante o periodo vitoriano, as roupas foram padronizadas, com botões à direita para os homens e à esquerda para as mulheres. Acreditava-se que o motivo para tanto era que as senhoras ricas eram vestidas por suas empregadas. A maioria das pessoas é destra e acha conveniente manusear o botão com a mão direita. Para os homens, que se vestiam sozinhos, o melhor lugar para haver botões era o lado direito. Isso foi invertido para as empregadas das senhoras, que viam de frente as roupas que abotoavam". Veja também: Veblen (2007).

[6] Veja Crawford (1970, p. 40). Conforme Windsor (1960, p. 95-97, traducão nossa): "Acessório essencial para o homem bem vestido do século XIX era a bengala. Sem dúvida, foi originada do chicote de equitação. Meu avô e meu pai nem sonhavam em sair sem portar uma dessas elegantes armas, com cabos ou punhos coroados com ouro ou casco de tartaruga, das quais ambos tinham amplas colecões, enquanto minha avó e minha mãe, e suas contemporâneas, levavam um guarda-sol. Os cavalheiros tinham bengalas especiais para a noite; alguns deles levavam pequenas espadas para autodefesa ao caminhar de volta a casa, tarde da noite". 


\section{REFERÊNCIAS}

ARAUJO, Marcelo de. Dom Pedro II e a moda masculina na época vitoriana. São Paulo: Estação das Letras e Cores, 2012.

ASSIS, Joaquim Maria Machado de. Quincas Borba. São Paulo: Cultrix, 1955.

BYRDE, Penelope. The male image: men's fashion in England 1300-1970. Londres:

Batsford, 1979.

CHRISP, Peter. A history of fashion and costume: the victorian age. Hove: Bailey, 2005.

CRAWFORD, T. S. A history of the umbrella. Nova York: Taplinger Publishing Company, 1970.

DIDEROT, Denis; D'ALEMBERT, Jean R. Encyclopédie ou dictionnaire raisonné des sciences, des arts et des métiers. V. 5. Paris: Briasson, 1781.

DONALD, Graeme. Loose cannons: 101 myths, mishaps and misadventurers of military history. Oxford: Osprey Publishing, 2009.

HIBBERT Clare; HIBBERT, Adam. A history of fashion and costume: the twentieth century. Hove: Bailey, 2005.

HUGO, Victor. Les miserables. V. 2. Londres: Wordsworth Classics, 1997.

JACOBS, Louis. Religion and the individual: a jewish perspective. Cambridge: Cambridge University Press, 2008.

MARLY, Diana de. Fashion for men: an illustrated history. Londres: Batsford, 1985.

MEYER, Arline. Re-dressing classical statuary: the eighteenth-century 'hand-in-waistcoat' portrait. The Art Bulletin. Reino Unido, v. 77, p. 45-63, mar. 1995.

NEVINSON, J. L. Buttons and buttonholes in the 14th century. Costume. Reino Unido, no 11, p. 38-44, 1977.

POLL, Solomon. The hasidic community of Williamsburg: a study in the sociology of religion. Nova Jersey: Transaction Publishers, 2006.

RABINOWICZ, Harry. Hasidism: the movement and its masters. Nova Jersey: Jason Aronson, 1989.

SCHOEFFLER, O. E.; GALE, William. Nehru suit and jacket. In: Esquire Encyclopedia of 20th Men's Fashions. Nova York: McGraw-Hill, 1973, p. 151-165.

VANDAM, Dresden. An englishman in Paris: reign of Louis Philippe. V. 1. Boston: Adamant Media Corporation, 2001.

VEBLEN, Thorstein. Dress as an expression of the pecuniary culture. In: leisure class. Oxford: Oxford University Press, 2007, p. 111-124. The theory of the

WATT, Melinda. Buttons. In: STEELE, Valerie (Org.). Encyclopedia of clothing and fashion. Farmington Hills: Thomson Gale, v. 1, 2005, p. 206-209.

WERTHEIM, Aaron. Laws and custom in hasidism. Nova York: Ktav Pub, 1992.

WHITE, Christopher; BUVELOT, Quentin (Org.). Rembrandt by himself. Londres: National Gallery London Publications, 1999.

WILDE, Oscar. Phrases and philosophies for the use of the young. In: The portable Oscar Wilde. Londres: Penguin, 1983.

WINDSOR, Edward Duke of. Windsor revisited. Boston: Houghton Mifflin, 1960. 